\title{
Avaliação da qualidade das Águas da Baia do Guajará para consumo humano
}

A população ribeirinha da ilha de Jutuba, pertencente ao município de Belém, não possui abastecimento público de água, sendo obrigada a recorrer ao consumo das águas da Baia do Guajará, bacia que banha a ilha, porém que recebe diariamente o despejo in natura do esgoto da cidade. Nesta perspectiva, o objetivo deste trabalho é avaliar a qualidade da água da Baia do Guajará utilizada para o consumo humano pela população ribeirinha da Ilha de Jutuba. Foram avaliadas as variáveis: cor aparente, turbidez, potencial hidrogeniônico, alcalinidade, sólidos dissolvidos totais, condutividade elétrica, dureza total, coliformes totais e Escherichia coli. As análises das amostras demonstraram que somente as variáveis sólidos totais dissolvidos, dureza total e $\mathrm{pH}$ apresentaram valores apropriados para ingestão, enquanto a cor aparente, turbidez, coliformes totais e Escherichia coli inadequados aos limites de potabilidade nacional.

Palavras-chave: Potabilidade; Ribeirinhos; Águas Naturais; Ingestão; Saúde.

\section{Assessment of the quality of Waters of Baia do Guajará for human consumption}

The riverside population of the island of Jutuba, belonging to the municipality of Belém, does not have a public water supply, being obliged to resort to the consumption of the waters of Baia do Guajará, a basin that bathes the island, but which receives daily the in natura dump of the city's sewage. In this perspective, the objective of this work is to evaluate the water quality of Baia do Guajará used for human consumption by the riverside population of Jutuba Island. The following variables were evaluated: apparent color, turbidity, hydrogenionic potential, alkalinity, total dissolved solids, electrical conductivity, total hardness, total coliforms and Escherichia coli.. The analyses of the samples showed that only the total dissolved solids, total hardness and pH variables presented appropriate values for intake, while the apparent color, turbidity, total coliforms and Escherichia coli were inadequate to the national potability limits.

Keywords: Potability; Ribeirinhos; Natural Waters; Ingestion; Cheers.

Topic: Química Agrícola e Ambiental

Reviewed anonymously in the process of blind peer.
Received: 04/10/2020

Approved: $\mathbf{2 1 / 1 1 / 2 0 2 0}$
Karen Albuquerque Dias da Costa (iD) Universidade Federal do Pará, Brasil http://lattes.cnpq.br/8493677235656139 http://orcid.org/0000-0002-1363-303X karenquimica123@yahoo.com.br

Jaisielle Kelem França Benjamim (iD) Universidade Federal do Pará, Brasil http://lattes.cnpq.br/7563800545443040 http.//orcidorg/0000-0001-9111-8167 jaisequimica@gmail.com

\section{Sabino Alves de Aguiar Neto}

Universidade Federal do Sul e Sudeste do Pará, Brasil

http://lattes.cnpq.br/7079838279336495 eng.sabinoneto@gmail.com

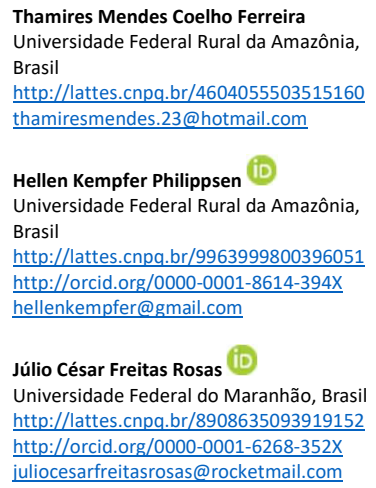

Thamires Mendes Coelho Ferreira Universidade Federal Rural da Amazônia, Brasil

http://lattes.cnpq.br/4604055503515160 thamiresmendes.23@hotmail.com

Hellen Kempfer Philippsen

Universidade Federal Rural da Amazônia, Brasil

http://lattes.cnpq.br/9963999800396051 http://orcid.org/0000-0001-8614-394X hellenkempfer@gmail.com

Júlio César Freitas Rosas (in

Universidade Federal do Maranhão, Brasil http://lattes.cnpq.br/890863509391915 http://orcid.org/0000-0001-6268-352X juliocesarfreitasrosas@rocketmail.com

\begin{tabular}{|l|} 
Ilka Suely Dias Serra \\
Instituto Federal do Pará, Brasil \\
http://lattes.cnpq.br/3476431016733666 \\
\hline$\underline{\text { ildiserra@yahoo.com.br }}$ \\
Jaqueline Maria Soares da Silva \\
Instituto Federal do Pará, Brasil \\
http://lattes.cnpq.br/0858733477253042 \\
jaquelineifpa@gmail.com \\
Maria do Socorro Bezerra Lopes (D) \\
Instituto Federal do Pará, Brasil \\
http://lattes.cnpq.br/1850698138869190 \\
http://orcid.org/0000-0003-1650-4724 \\
soclopes@gmail.com
\end{tabular}

Cezarina Maria Nobre Souza (iD Instituto Federal do Pará, Brasil http://lattes.cnpq.br/4638345244640854 http://orcid.org/0000-0002-2430-4653 cezarina.souza@ifpa.edu.br
Referencing this:

COSTA, K. A. D.; BENJAMIM, J. K. F.; AGUIAR NETO, S. A.; FERREIRA, T. M. C.; PHILIPPSEN, H. K.; ROSAS, J. C. F.; SERRA, I. S. D.; SILVA, J. M. S. LOPES, M. S. B.; SOUZA, C. M. N.. Avaliação da qualidade das Águas da Baia do Guajará para consumo humano. Revista Ibero Americana de Ciências Ambientais, v.11, n.6, p.150-159, 2020. DOI: http://doi.org/10.6008/CBPC2179-6858.2020.006.0014 


\section{INTRODUÇÃO}

A escassez da água é uma ameaça crescente que assola o mundo inteiro, principalmente países em desenvolvimento (MAHMOOD et al., 2017; MUSAYEV et al., 2018; ZDEB et al., 2020). As mudanças climáticas, a explosão demográfica e o aumento da poluição dos corpos d'água são os principais fatores para a consolidação desta crise hídrica (AL-BATSH et al., 2019; CLARK et al., 2019; COSTA et al., 2020; SANTOS et al., 2017). Dispor de água limpa é um direito essencial do ser humano, necessário para sua sobrevivência e para o progresso da população (TERÊNCIO et al., 2018). A falta de água potável é responsável por $80 \%$ das enfermidades ocorrentes em países pobres, como por exemplo, o Quênia, Índia, Uganda, Bangladesh, Paquistão, Nepal, Butão, Siri Lanka e Bolívia (FUENTES-GALVÁN et al., 2018; KEOGH et al., 2017; MAHMOOD et al., 2017; QUAGHEBEUR et al., 2019), sendo a disenteria, a febre tifoide e a cólera as doenças de maior prevalência (CLARK et al., 2019; GÓMEZ-COUSO et al., 2012; LAWRIE et al., 2015; MAHMOOD et al., 2017; NALWANGA et al., 2018). No Brasil esta realidade não é diferente, sendo as populações rurais e urbanas de baixa renda as mais afetadas, das quais as comunidades ribeirinhas amazônicas estão entre as mais marginalizadas.

Os ribeirinhos são pequenas comunidades tradicionais, localizadas ao longo dos rios e seus afluentes, em regiões afastadas dos centros urbanos e as proximidades de áreas de floresta nativa (NASCIMENTO et al., 2017; LIRA et al., 2016). São compostas por várias famílias que sobrevivem a partir da agricultura de subsistência, da pesca, do extrativismo (principalmente do açaí), da criação de pequenos animais (galinhas, porcos e patos) e do artesanato (LIRA et al., 2016; PEREIRA et al., 2019). Esta população, em sua grande maioria, possuem renda abaixo de 1 salário mínimo e sofrem com o analfabetismo ou possuem somente $o$ ensino fundamental, habitam em moradias de madeira suspensas sobre os rios, denominadas de palafitas, e convivem com inúmeras precariedades, como a insegurança, baixo acesso à energia elétrica, educação, saúde e saneamento básico (LOBO et al., 2013; PEREIRA et al., 2019).

Os moradores da llha de Jutuba, assim como os das demais 39 ilhas pertencentes a região Insular de Belém, capital do Estado do Pará, sofrem com a falta de esgotamento sanitário e com a ausência do abastecimento público de água e, em decorrência de estarem em uma área de inundação recorrente e diária, são impedidos de obter água através do lençol freático (LOBO et al., 2013). Frente esta realidade, quando as condições financeiras permitem, estes indivíduos deslocam-se para a região continental para comprar água de boa qualidade, entretanto quando os recursos financeiros são escassos, são obrigados a consumir diretamente água inapropriada da Baia do Guajará, bacia que banha a ilha, porém que recebe diariamente o despejo in natura do esgoto de Belém (COSTA et al., 2020; LOBO et al., 2013).

Nesta perspectiva, o objetivo deste trabalho é avaliar a qualidade da água da Baia do Guajará armazenada para o consumo humano pela população ribeirinha da llha de Jutuba, pertencente ao munícipio de Belém-PA. 


\section{MATERIAIS E MÉTODOS}

\section{Local de coleta}

Este estudo foi realizado na llha de Jutuba, localizada no munícipio de Belém, capital do Estado do Pará. Esta ilha é banhada pela Baia do Guajará e possui coordenada geográfica S $01^{\circ} 14^{\prime} 46,4^{\prime \prime} /$ W $048^{\circ} 30^{\prime}$ $28,5^{\prime \prime}$. A Figura 01 apresenta a localização desta ilha.

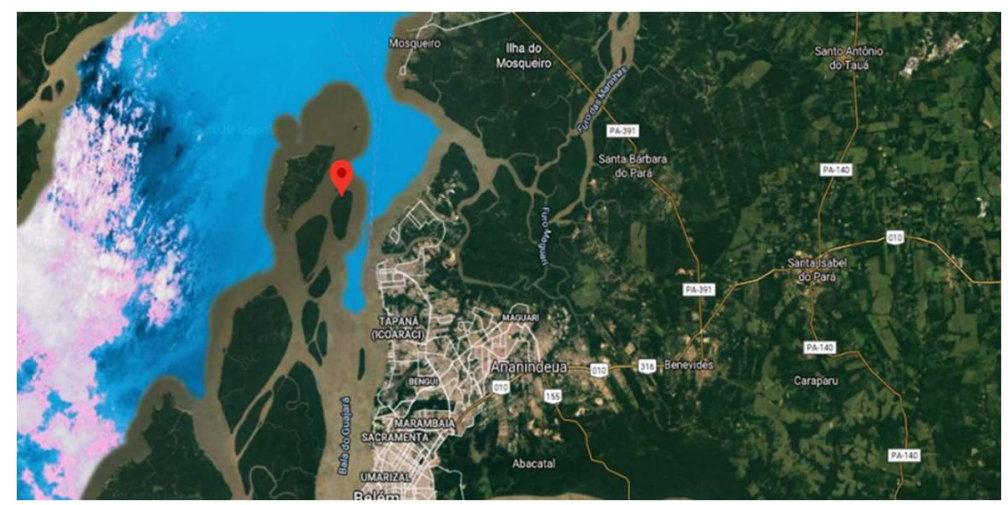

Figura 1: Localização da Ilha de Jutuba.

\section{Amostragem}

No reservatório utilizado pelos moradores da llha de Jutuba para o armazenamento da água do Rio Maguari para consumo humano foram coletadas 10 amostras de $1000 \mathrm{~mL}$, em frascos de polietileno, para avaliação das variáveis físico-químicas e 10 amostras de $200 \mathrm{~mL}$, em frascos de polipropileno previamente esterilizadas em autoclave, a $121^{\circ} \mathrm{C}$, durante 30 minutos, para a determinação das variáveis microbiológicas. Após a coleta, todas as amostras foram identificadas, armazenadas sob refrigeração e em seguida transportadas para os laboratórios de Qualidade das Águas do Instituto Federal de Educação, Ciência e Tecnologia do Pará (IFPA). As amostras foram coletadas em diferentes momentos climatológicos do município de Belém: o período chuvoso (dezembro a maio), período de estiagem (julho a outubro) e o período intermediário (julho e novembro).

\section{Variáveis físico-químicas e microbiológicas}

Foram avaliadas as variáveis: cor aparente (COR), turbidez (TRB), potencial hidrogeniônico $(\mathrm{pH})$, alcalinidade (ALC), sólidos dissolvidos totais (STD), condutividade elétrica (CE), dureza total (DT), Coliformes Totais (CT) e Escherichia coli (E. coli). A cor aparente foi mensurada empregando um espectrofotômetro Hach, Modelo DR 2500. A turbidez foi quantificada em um Turbidímetro Alfakit, Modelo Microprocessado Plus. Os valores de $\mathrm{pH}$, condutividade elétrica, sólidos totais dissolvidos foram medidos em um aparelho multiparâmetros HANNA Instruments, Modelo HI 255. A alcalinidade e a dureza total foram quantificadas por métodos titulométricos. A variável bacteriológica foi determinada pelo método do substrato cromogênico, com a técnica colillert - Quanti tray - 2000. Todos os procedimentos de amostragem, 
armazenamento, preservação e análise das amostras foram realizados conforme as recomendações do manual prático de análise de água e das normas descritas no Standard methods for examination of water and wastewater (APHA et al., 1988; BRASIL, 2006).

\section{Tratamento estatístico dos dados}

Os dados analíticos deste trabalho foram interpretados empregando-se ferramentas da estatística descritiva univariada (média, mínimo, máximo) e comparados com as orientações brasileiras para águas destinadas ao consumo humano. Foram empregados o software pago Microsoft Excel e o software livre BioStat 5.0, desenvolvido pela Universidade Federal do Pará.

\section{RESULTADOS}

A qualidade da água da Baia do Guajará, consumida pela comunidade ribeirinha da llha de Jutuba, foi avaliada frente a Legislação Brasileira de Potabilidade. Os valores médios, mínimos e máximos das variáveis físico-químicas e microbiológicas são apresentados na Tabela 1.

Tabela 1: Resultados das variáveis físico-químicas e microbiológicas das amostras de água da bacia do Guajará.

\begin{tabular}{l|l|l|l|l}
\hline Variáveis & Unidades & Média & Mínimo-Máximo & Limites Nacionais \\
\hline COR & UH & 93,8 & $25-206$ & 15 \\
TRB & UT & 6,1 & $1,6-12,5$ & 5 \\
STD & $\mathrm{mg} / \mathrm{L}$ & 208,1 & $20,9-771$ & 1000 \\
$\mathrm{CE}$ & $\mathrm{HS} / \mathrm{cm}$ & 419,2 & $21,07-1503$ & - \\
$\mathrm{DT}$ & $\mathrm{mg} / \mathrm{L}$ & 49,87 & $11-92$ & 500 \\
$\mathrm{pH}$ & - & 7,4 & $6,8-8,88$ & $6-9,5$ \\
$\mathrm{ALC}$ & $\mathrm{mg} / \mathrm{L}$ & 15,3 & $2-38$ & - \\
$\mathrm{ACD}$ & $\mathrm{mg} / \mathrm{L}$ & 5,7 & $1-16$ & - \\
$\mathrm{CT}$ & $\mathrm{NMP} / 100 \mathrm{~mL}$ & 200,53 & $14,6-613,1$ & 0 \\
E.coli & $\mathrm{NMP} / 100 \mathrm{~mL}$ & 12,75 & $1-28,8$ & 0 \\
\hline
\end{tabular}

A Cor Aparente (COR) das amostras apresentou valor médio de 93,8 UT, oscilando entre 25 a 206 UT, valores superiores a $15 \mathrm{UH}$, limite máximo permitido pela legislação nacional. De modo semelhante, a Turbidez (TRB) média das amostras foi superior ao máximo permitido de 5 UT para fins potáveis, com valor médio igual a 6,1 UT, oscilando entre 1,6 a 12,5 UT.

Os Sólidos Totais Dissolvidos (STD), pH e Dureza Total (DT) apresentaram valores satisfatórios frente os parâmetros de potabilidade brasileiro. A concentração média de STD foi igual a 208,1 mg/L, variando 20,9 a $771 \mathrm{mg} / \mathrm{L}$, valores abaixo do limite de $1000 \mathrm{mg} / \mathrm{L}$. O pH médio foi igual a 7,4, oscilando entre 6,8 a 8,88, estando dentro da faixa de 6-9,5 definido como ideal para águas destinadas ao consumo humano e DT apresentou valor médio igual a 49,87 mg/L, apresentando mínimo de $11 \mathrm{mg} / \mathrm{L}$ e máximo $92 \mathrm{mg} / \mathrm{L}$, quantidades de acordo com o limite nacional de $500 \mathrm{mg} / \mathrm{L}$. A condutividade elétrica (CE), a alcalinidade (ALC) e acidez ( $A C D)$ não são variáveis indicadas na legislação de potabilidade, entretanto são úteis para uma melhor descrição do comportamento das amostras. A CE média foi 419,2 $\mu \mathrm{S} / \mathrm{cm}$, variando de 21,07 a 1503 $\mu \mathrm{S} / \mathrm{cm}$. A ALC média foi $15,3 \mathrm{mg} / \mathrm{L}$, variando de $2-38 \mathrm{mg} / \mathrm{L}$ e a $A C D$ apresentou média $5,7 \mathrm{mg} / \mathrm{L}$, variando entre 1 a $16 \mathrm{mg} / \mathrm{L}$. 
Para a avaliação da qualidade microbiológica da Bacia do Guajará como fonte de água para o consumo humano, quantificaram-se os Coliformes Totais (CT) e Escherichia coli (E. coli). A Legislação Brasileira define que estes indicadores devem ser ausentes a cada $100 \mathrm{~mL}$ de água, todavia todas as amostras apresentaram níveis inadequados para o consumo humano, com valor médio de CT igual a 200,53 $\mathrm{NMP} / 100 \mathrm{~mL}$, oscilando entre 14,6 e 613,1 NMP/100mL e E. coli igual a 12,75NMP/100mL, variando entre 1 a $28,8 \mathrm{NMP} / 100 \mathrm{~mL}$.

Comparando-se os períodos sazonais, observou-se que os valores de cor aparente para o período chuvoso, foi superior ao período seco, com valores médios 80,5 UH e 76,6 UH, respectivamente. Em ambos períodos, a CA apresentou valores superiores ao Limite Nacional (15 UH), conforme é ilustrado na Figura 2.

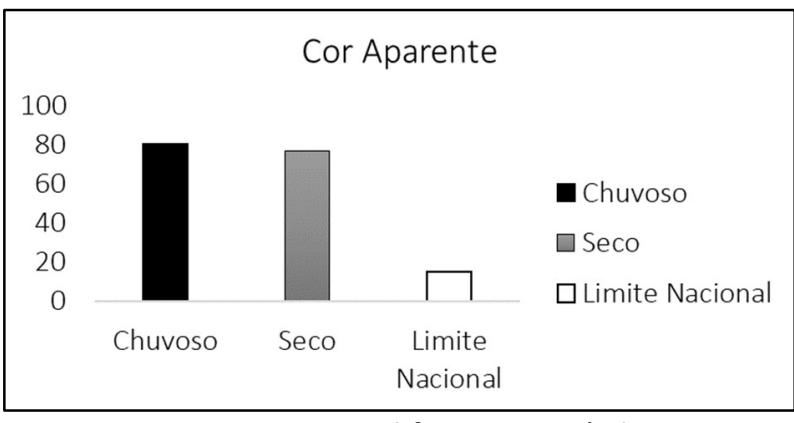

Figura 2: Cor Aparente em diferentes períodos sazonais.

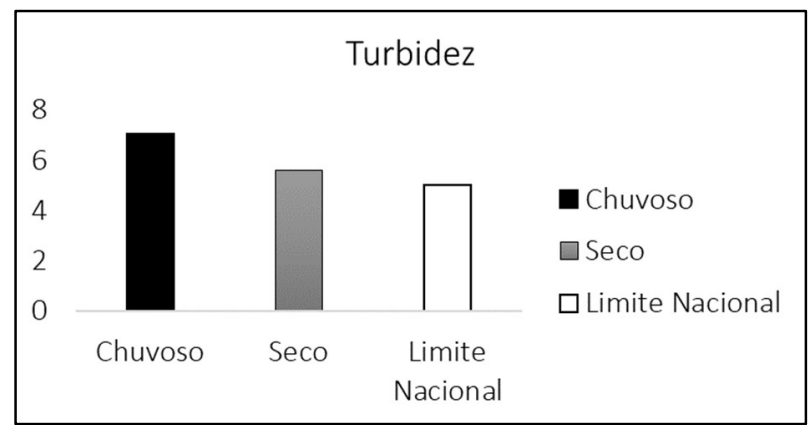

Figura 3: Turbidez em diferentes períodos sazonais.

Comportamento semelhante foi observado nos níveis de turbidez, onde a média para o período chuvoso foi 7,05 UT e para o período seco de 5,61 UT, ambos acima do Limite Nacional (5 UT). A Figura 3 apresenta estes resultados.

No que diz respeito a concentração dos sólidos totais dissolvidos, observou-se que em ambos períodos sazonais as concentrações permaneceram dentro dos limites de potabilidade, todavia a concentração de STD no período seco foi superior ao período chuvoso. A Figura 4 ilustra o comportamento desta variável.

As amostras apresentaram teores de dureza total adequados aos limites nacionais. Observou-se que as amostras coletadas no período de maior pluviosidade apresentaram valores médios de DT inferiores as amostras coletadas no período de estiagem, conforme é ilustrado na Figura 5.

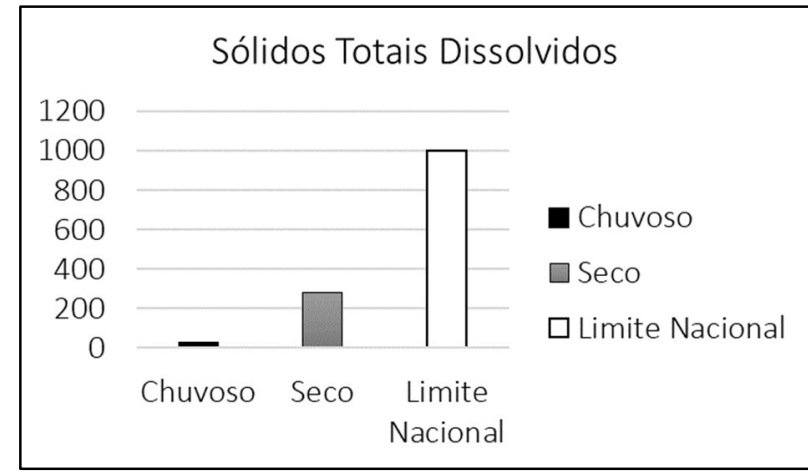

Figura 4: Sólidos Totais Dissolvidos em diferentes períodos sazonais.

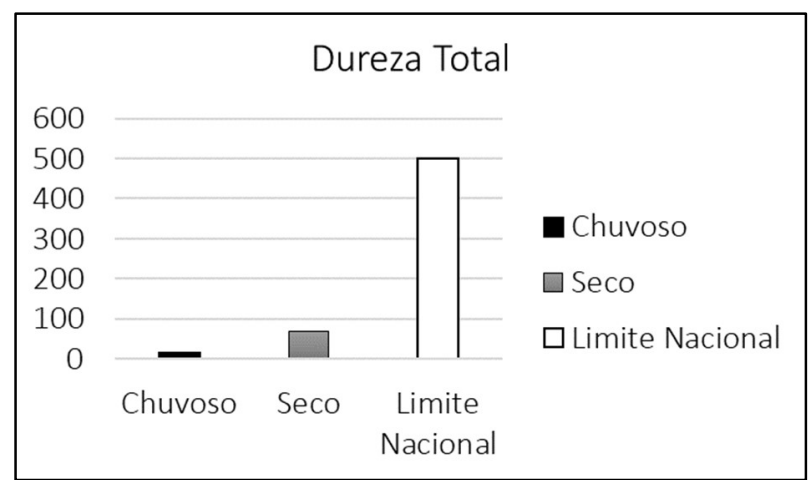

Figura 5: Dureza Total em diferentes períodos sazonais. 
Não foram observadas diferenças significativas nos valores de $\mathrm{pH}$ em diferentes períodos sazonais. Todavia, no que diz respeito a alcalinidade, as amostras coletadas no período chuvoso apresentaram teores superiores aos quantificados no período seco. Este comportamento é ilustrado na Figura 6.

De maneira contrária, as amostras coletadas no período chuvoso apresentaram níveis de acidez inferiores as amostras coletadas no período seco, conforme é mostrado na Figura 7.

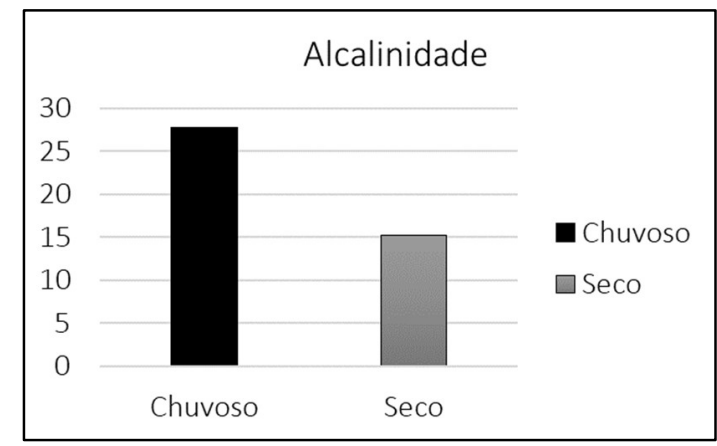

Figura 6: Alcalinidade em diferentes períodos sazonais.

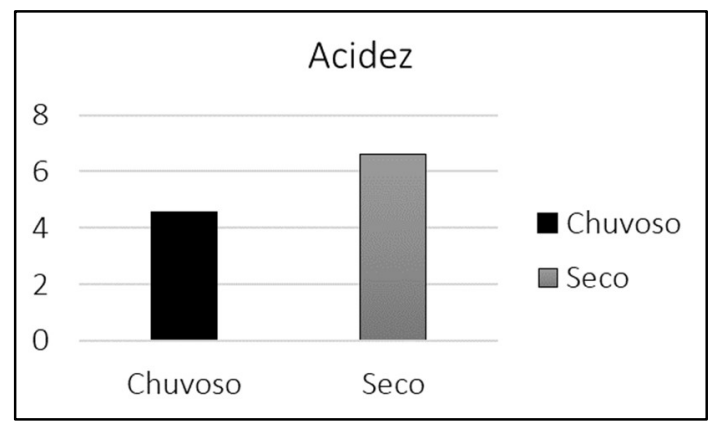

Figura 7: Acidez em diferentes períodos sazonais.

Nos aspectos bacteriológicos, não foram observadas diferenças significativas nos níveis de coliformes totais entre os períodos sazonais. Entretanto, no que se refere as concentrações de Escherichia coli, observou-se que as concentrações deste microrganismo foram superiores no período de maior precipitação, como é apresentado na Figura 8.

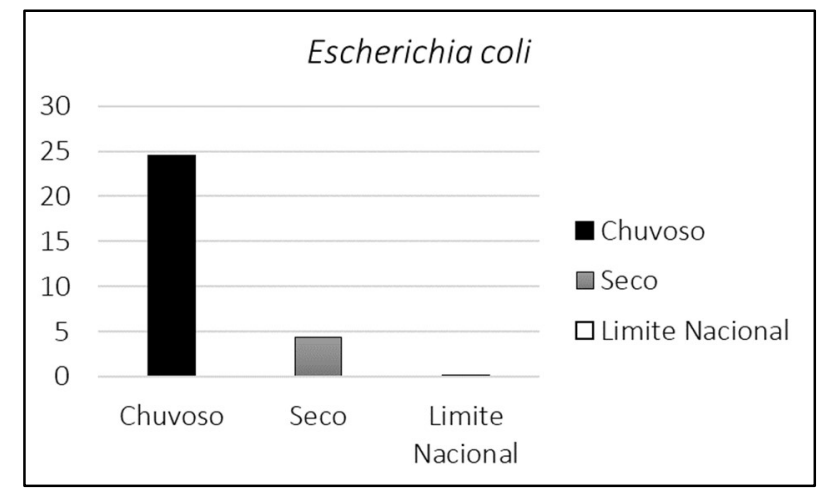

Figura 8: Escherichia coli em diferentes períodos sazonais.

\section{DISCUSSÃO}

As principais fontes de água para as comunidades ribeirinhas amazônicas, como a pertencente a llha de Jutuba, são os rios e seus afluentes (COSTA et al., 2020). A qualidade da água destas fontes pode ser afetada por fatores como geoquímica e volume de vegetação circundante, variações climáticas, regime de chuvas, dinâmica das atividades antrópicas nas margens dos rios e a intensidade de lançamento de contaminantes domésticos e industriais (ANDRIETTI et al., 2016; ABREU et al., 2017). Neste sentido, a quantificação de parâmetros físico-químicos e microbiológicos é fundamental para a avaliação da qualidade destas fontes naturais de abastecimento de água para estas comunidades. As análises das amostras de águas da Baia do Guajará demonstraram que somente as variáveis sólidos totais dissolvidos, dureza total e pH apresentaram valores apropriados para ingestão, enquanto a cor aparente, turbidez, coliformes totais e 
Escherichia coli inadequados aos limites de potabilidade nacional.

A cor aparente de águas superficiais é uma variável físico-química resultante da presença de sólidos dissolvidos ou em suspensão, que podem ser de origem natural, como ácidos húmicos e taninos, gerados do processo de decomposição de matéria orgânica não apresentando efeitos adversos a saúde humana (DA SILVA et al., 2017), ou podem ser de origem antropogênica através de lançamento de efluentes industrias ricos em corantes artificiais produzidos a partir de metais pesados, os quais apresentam elevada toxidade (SILVA et al., 2017; FERREIRA et al., 2015). As águas da Baia do Guajará por apresentarem coloração não são desejáveis para o consumo humano, seja por questões estéticas, quanto por sinalizarem possíveis níveis de contaminação. Além disso, podem oferecer prejuízos ao ecossistema aquático, afetando a visibilidade de algumas espécies na busca por alimentos (ABREU et al., 2017).

A turbidez é uma variável que mensura o potencial de penetração de um feixe de luz em um corpo d'água e é intimamente relacionada com a quantidade de sólidos suspensos no mesmo ambiente (RAHMANIAN et al., 2015; SANTOS et al., 2020). A presença de altos níveis de turbidez pode influenciar na sobrevivência de animais e plantas aquáticas, afetando as reações de fotossíntese e reduzindo a disponibilidade de oxigênio (CAZASSA et al., 2018; ABREU et al., 2017). No que se refere a potabilidade, as águas da Baia do Guajará apresentam turbidez superior aos permitidos pela legislação, não sendo apropriadas para o consumo, pois seus sólidos suspensos atuam como abrigo e alimento para microrganismos (RAHMANIAN et al., 2015).

A presença de coliformes totais e Escherichia coli nas amostras analisadas indicam a presença de contaminação por esgoto doméstico, haja vista que estes microrganismos habitam a flora intestinal de animais superiores, como seres humanos e outros mamíferos, o que sinaliza um elevado risco de contaminação de outros agentes patogênicos como os responsáveis por doenças de veiculação hídrica (KUMAR et al., 2012; SANTOS et al., 2020; ZDEB et al., 2020). Dispor de água potável é uma necessidade essencial de cada ser humano, seu consumo a partir de fontes contaminadas representa um grave problema de saúde pública, principalmente para a população infantil com até 5 anos de idade, que podem ser acometidas de doenças gastrointestinais (POLO-LÓPEZ et al., 2019; MAHMOOD et al., 2017; NALWANGA et al., 2018). Vários microrganismos e parasitas patogênicos são de veiculação hídrica, tais como a Salmonela typhi, Salmonela paratiphi A e B, Shigella spp., Vibrio cholerae, Escherichia coli enterotóxica, Campylobacter, Yersinia enterocolítica, Salmonela spp., Entamoeba histolytica, Giardia Iamblia, Cryptosporidium, vírus da hepatite A e B, vírus da poliomielite, vírus Norwalk, rotavírus, enterovírus e adenovírus. Estes agentes são causadores de doenças como febre tifoide e paratifoide, disenteria bacilar, cólera, gastroenterite aguda e diarreias, hepatite A e B, poliomielite e disenteria amebiana (AYANDIRAN et al., 2018; COSTA et al., 2020; LAWRIE et al., 2015).

$\mathrm{O}$ pH é uma importante variável que permite indicar o nível de acidez e alcalinidade de um sistema (KUMAR et al., 2012; RAHMANIAN et al., 2015) e sua magnitude é influenciada principalmente pela concentração de $\mathrm{CO}_{2}$ dissolvido e pelo teor da alcalinidade total presente no corpo d'água (SILVA et al., 2017). 
Corpos d'água com pH oscilando entre 6 e 9,5 apresentaram valores adequados para a manutenção da homeostase de sua população de peixes e invertebrados e satisfatórios para fins potáveis, sendo úteis para beber e para a irrigação de plantio (KUMAR et al., 2012; ŞENER et al., 2017).

Os sólidos totais dissolvidos exprimem o conjunto das substâncias orgânicas e inorgânicas solubilizadas em um curso d'água e a concentração destas substâncias pode influenciar nos aspectos organolépticos, conferindo sabor salobro ou salino para as águas (MORAIS et al., 2015; UDHAYAKUMAR et al., 2016). Outro aspecto a ser observado, é que altos níveis de sólidos totais dissolvidos podem causar problemas gástricos e formação de cálculos renais (UDHAYAKUMAR et al., 2016). Esta variável pode ser influenciada por contaminação antrópica ou por características geológicas ou climáticas, sendo seu teor comumente mais elevado em períodos de estiagem (AYANDIRAN et al., 2018; SILVA et al., 2017).

A condutividade elétrica é uma variável que mensura a capacidade de uma amostra de água conduzir eletricidade (RAHMANIAN et al., 2015). Em águas naturais está associada a concentração dos sólidos totais dissolvidos de natureza salina, que em meio aquoso dissociam-se e liberam espécies iônicas de caráter positivo e negativo (ANDRIETTI et al., 2016; ŞENER et al., 2017), estas espécies podem ser de origem natural ou de origem antropogênica, como despejo de esgotos domésticos (CHAVES et al., 2020; SANTOS et al., 2020; ZDEB et al., 2020). Altos valores de condutividade elétrica são indesejáveis para águas destinadas ao consumo humano, pois confere-Ihe sabor mineral além de apresentar risco de corrosão de superfícies metálicas (RAHMANIAN et al., 2015).

A dureza de águas superficiais tem origens geoquímicas e corresponde a totalidade das concentrações de carbonatos, bicarbonatos, sulfatos e cloretos de cálcio e magnésio e em menor proporção de alumínio e ferro (BARAKAT et al., 2018; KUMAR et al., 2012; MALAKOOTIAN et al., 2010; UDHAYAKUMAR et al., 2016). Águas com elevados níveis de dureza são inapropriadas para a ingestão, por estarem associadas a incidência de problemas cardíacos e renais (MALAKOOTIAN et al., 2010; UDHAYAKUMAR et al., 2016).

\section{CONCLUSÕES}

Os resultados das análises físico-químicas e microbiológicas das amostras de água da Baia do Guajará utilizadas para o consumo humano na comunidade ribeirinha da llha de Jutuba indicaram que este recurso natural não está de acordo com os parâmetros de potabilidade nacional, sendo que seu consumo representa riscos à saúde desta população, com a possibilidade de doenças de veiculação hídrica com diarreia e cólera. Sugere-se o aproveitamento da água de chuva associado a um sistema de desinfecção de baixo custo, como a desinfecção solar (SODIS) ou a cloração para a ingestão humana.

AGRADECIMENTOS: Os autores gostariam de agradecer ao Conselho Nacional de Desenvolvimento Científico e Tecnológico (CNPQ, Brasília, Distrito Federal, Brasil), pelo suporte financeiro desta pesquisa (Edital MCT/CTSAÚDE/CT-HIDRO/CNPq N 45/2008), pela concessão de bolsa de mestrado a K.A.D.C (CNPq processo: 135151/2010-4), e a Caritas Metropolitana de Belém (CAMEBE, Belém, Pará, Brasil) por fornecer os meios de 
transporte para as visitas em campo.

\section{REFERÊNCIAS}

ABREU, C. H. M.; CUNHA, A. C.. Qualidade da água e índice trófico em rio de ecossistema tropical sob impacto ambiental. Engenharia Sanitária e Ambiental, v.22, n.1, p.45-56, 2017. DOI: http://dx.doi.org/10.1590/s141341522016144803

AL-BATSH, N.; AL-KHATIB, I. A.; GHANNAM, S.; ANAYAH, F.; JODEH, S.; HANBALI, G.; KHALAF, B.; VALK, M, V. D.. Assessment of rainwater harvesting systems in poor rural communities: A case study from Yatta Area, Palestine.

Water, v.11, n.3, p.1-15, 2019. DOI:

https://doi.org/10.3390/w11030585

ANDRIETTI, G.; FREIRE, R.; AMARAL, A. G.; ALMEIDA, F. T.; BONGIOVANI, M. C.; SCHNEIDER, R. M.. Índices de qualidade da água e de estado trófico do rio Caiabi, MT. Revista Ambiente e Água, v.11, n.1, p.162-175, 2016. DOI: https://doi.org/10.4136/ambi-agua.1769

APHA; AWWA; WEF. American Public Health Association; American Water Works Association; World Economic Forum. Standard methods for the examination of water and wastewater. 20 ed. Washington: APHA, 1988.

AYANDIRAN, T. A.; FAWOLE, O. O.; DAHUNSI, S. O.. Water quality assessment of bitumen polluted Oluwa River, SouthWestern Nigeria. Water Resources and Industry, v.19, p.1324, 2017, 2018. DOI:

https://doi.org/10.1016/j.wri.2017.12.002

BARAKAT, A.; MEDDAH, R.; AFDALI, M.; TOUHAMI, F. Physicochemical and microbial assessment of spring water quality for drinking supply in Piedmont of Béni-Mellal Atlas (Morocco). Physics and Chemistry of the Earth, v.104, p.3946, 2018. DOI: https://doi.org/10.1016/j.pce.2018.01.006

BRASIL. Manual Prático de Análise de Água. 4 ed. Brasília: Fundação Nacional de Saúde, 2006.

CAZASSA, G. C.; SANTOS, M. C.; OLIVEIRA, T. G.; PEREIRA, P. H. R.; GONÇALVES, J. A. C.. Monitoramento de desastres em rios empregando sensoriamento remoto: análise comparativa da turbidez e da reflectância no Rio Doce. Revista Ibero-Americana de Ciências Ambientais, v.9, n.5, p.308-318, 2018. DOI: https://doi.org/10.6008/CBPC2179$\underline{6858.2018 .005 .0027}$

CHAVES, H. S.; MORAIS, D. G.; COSTA, K A. D.; OLIVEIRA, I. V.; DANTAS, K. G. F.; SILVA, C. R.; SILVA, J. P.; SILVA, J. N.; SILVA, V. F. A.; SILVA, P. A.. Estudo da qualidade das águas subterrâneas de abastecimento em bairros na cidade de parauapebas a partir de parâmetros físico-químicos. Revista Ibero-Americana de Ciências Ambientais, v.11, n.3, p.113121, 2020. DOI: https://doi.org/10.6008/CBPC21796858.2020 .003 .0011

CLARK, G. G.; JAMAL, R.; WEIDHAAS, J.. Roofing material and irrigation frequency influence microbial risk from consuming homegrown lettuce irrigated with harvested rainwater. Science of the Total Environment, v.651, p.1011-1019, 2019. DOI: https://doi.org/10.1016/j.scitotenv.2018.09.277
COSTA, K. A. D.; CARVALHO, F. I. M.; FERREIRA, F. D. P. B.; NASCIMENTO, T. V.; MELLO, R. F. A.; SERRA, I. S. D.; LOPES, M. S. B.; SOUZA, C. M. N.; DANTAS, K. G. F.; FILHO DANTAS, H. A.. Influência do tipo de telhado na qualidade da água de chuva coletada em comunidades ribeirinhas. Revista IberoAmericana de Ciências Ambientais, v.11, n.3, p.384-391, 2020. DOI: https://doi.org/10.6008/CBPC21796858.2020 .003 .0029

FERREIRA, A. C.; ROCHA, L. C.; FIGUEIREDO, M. D. A.. Análise do índice de qualidade de água na bacia do córrego do rio acima, São João Del-Rei/Mg. Revista Nacional de Gerenciamento de Cidades, v.3, n.15, p.94-105, 2015. DOI: http://dx.doi.org/10.17271/231884723152015994

FUENTES-GALVÁN, M. L.; MEDEL, J. O.; ARIAS HERNÁNDEZ, L. A.. Roof rainwater harvesting in central Mexico: Uses, benefits, and factors of adoption. Water, v.10, n.2, 2018. DOI: https://doi.org/10.3390/w10020116

GÓMEZ-COUSO, H. SAINZ, M. F.; FERNADEZ-IBÁNEZ, P.; ARES-MAZÁS, E.. Speeding up the solar water disinfection process (SODIS) against Cryptosporidium parvum by using 2.5 I static solar reactors fitted with compound parabolic concentrators (CPCs). Acta Tropica, v.124, n.3, p.235-242, 2012. DOI:

https://doi.org/10.1016/j.actatropica.2012.08.018

KEOGH, M. B.; ELMUSHARAF, K.; BORDE, P.; MCGUIGAN, K. G.. Evaluation of the natural coagulant Moringa oleifera as a pretreatment for SODIS in contaminated turbid water. Solar Energy, v.158, p.448-454, 2017. DOI: https://doi.org/10.1016/i.solener.2017.10.010

KUMAR, M.; PURI, A.. A review of permissible limits of drinking water. Indian Journal of Occupational and Environmental Medicine, v.16, n.1, p.40-44, 2012.

LAWRIE, K.; MILLS, A.; FIGUEIREDO-FERNÁNDEZ, M.; GUITIÉRREZ-ALFARO, S.; MANZANO, M.; SALADIN, M.. UV dosimetry for solar water disinfection (SODIS) carried out in different plastic bottles and bags. Sensors and Actuators, B: Chemical, v.208, p.608-615, 2015. DOI: https://doi.org/10.1016/j.snb.2014.11.031

LIRA, T. D. M.; CHAVES, M. D. P. S. R.. Comunidades Ribeirinhas na Amazônia: organização sociocultural e política. Interações, Campo Grande, v.17, n.1, p.66-76, 2016. DOI: http://dx.doi.org/10.20435/1518-70122016107

LOBO, M. A. A.; LIMA, D. M. B.; SOUZA, C. M. N.; NASCIMENTO, W. A.; ARAÚJO, L. C. C.; SANTOS, N. B.. Avaliação econômica de tecnologias sociais aplicadas à promoção de saúde: Abastecimento de água por sistema Sodis em comunidades ribeirinhas da Amazônia. Ciência e Saúde Coletiva, v.18, n.7, p.2119-2127, 2013. DOI: http://dx.doi.org/10.1590/S1413-81232013000700027

MAHMOOD, A.; HOSSAIN, F.. Feasibility of managed domestic rainwater harvesting in South Asian rural areas 
using remote sensing. Resources, Conservation and Recycling, v.125, p.157-168, 2017. DOI:

https://doi.org/10.1016/j.resconrec.2017.06.013

MALAKOOTIAN, M.; MANSOORIAN, H. J.; MOOSAZADEH, M.. Performance evaluation of electrocoagulation process using iron-rod electrodes for removing hardness from drinking water. Desalination, v.255, n.1-3, p.67-71, 2010. DOI: https://doi.org/10.1016/j.desal.2010.01.015

MORAIS, R. C. S.; ARAÚJO, I. R. G.. Análise espacial da concentração de sólidos totais dissolvidos (STD) em águas subterrâneas da região norte do Piauí. Revista Equador, v.4, n.4, p.67-80, 2015.

MUSAYEV, S.; BURGESS, E.; MELLOR, J.. A global performance assessment of rainwater harvesting under climate change. Resources, Conservation and Recycling, v.132, p.62-70, 2018. DOI: https://doi.org/10.1016/j.resconrec.2018.01.023

NALWANGA, R.; MUYANJA, C. K.; MCGUIGAN, K. G.; QUILTY, B.. A study of the bacteriological quality of roof-harvested rainwater and an evaluation of SODIS as a suitable treatment technology in rural Sub-Saharan África. Journal of Environmental Chemical Engineering, v.6, n.3, p.3648-3655, 2018. DOI: https://doi.org/10.1016/j.jece.2016.12.008

NASCIMENTO, R. G.; CARDOSO, R. O.; DOS SANTOS, Z. N. L.; PINTO, D, S.; MAGALHÂES, C. M. C.. Housing conditions and the degree of home satisfaction of elderly riverside residents of the Amazon region. Psico-USF, v.22, n.3, p.389-399, 2017. DOI: http://dx.doi.org/10.1590/1413-82712017220301

PEREIRA, L. T.; SIQUEIRA, L. S.; CORREA, V. A. C.; ARAÚJO, L. S.; FOLHA, O. A. A. C.. Caracterização das ocupações de moradores de uma comunidade ribeirinha na Amazônia brasileira. Colégio Colombiano de Terapia Ocupacional, v.18, n.2, p.5-19, 2019. DOI:

https://doi.org/10.25214/25907816.232

POLO-LÓPEZ, I.; MARTÍNEZ-GARCIA, A.; ABELEDO-LAMEIRO, M. J.; GÓMEZ-COUSO, H. H.; ARES-MAZÁS, E. E.; REBOREDODERMÁNDEZ, A.; MORSE, T. D.; BUCK, L.; LUNGU, K.; MCGUIGAN, K. G.; FERNÁNDEZ-IBÁNEZ, P.. Microbiological evaluation of $5 \mathrm{~L}$ - And $20 \mathrm{~L}$-transparent polypropylene buckets for solar water disinfection (SODIS). Molecules, v.24, n.11, 2019. DOI:

https://doi.org/10.3390/molecules24112193

QUAGHEBEUR, W.; MULHERN, R. E.; RONSSE, S.; HEYLEN, S.;
BLOMMAERT, H.; POTEMANS, S.; MENDIZÁBAL, C. V.; GRACÍA, J. T.. Arsenic contamination in rainwater harvesting tanks around Lake Poopó in Oruro, Bolivia: An unrecognized health risk. Science of the Total Environment, v.688, p.224230, 2019. DOI:

https://doi.org/10.1016/j.scitotenv.2019.06.126

RAHMANIAN, N.; ALI, S, H. B.; HOMAYOONFARD, M.; ALI, M. J.; REHAN, M.; SADEF, Y.; NIZAMI, A. S.. Analysis of physiochemical parameters to evaluate the drinking water quality in the state of perak, Malaysia. Journal of Chemistry, v.2015, 2015. DOI: https://doi.org/10.1155/2015/716125

SANTOS, L. F.; MARINHO, E. R.; MOREIRA, F. S. A.; CARNEIRO, B. S.; FAIAL, K. C. F.. Avaliação da qualidade da água da baía do Guajará em Belém/PA. Revista IberoAmericana de Ciências Ambientais, v.11, n.2, p.367-380, 2020. DOI: https://doi.org/10.6008/CBPC21796858.2020 .002 .0034

SANTOS, S. M.; FARIAS, M. M. M. W. E. C.. Potential for rainwater harvesting in a dry climate: Assessments in a semiarid region in northeast Brazil. Journal of Cleaner Production, v.164, p.1007-1015, 2017. DOI: https://doi.org/10.1016/j.jclepro.2017.06.251

ŞENER, Ş.; ŞENER, E.; DAVRAZ, A.. Evaluation of water quality using water quality index (WQI) method and GIS in Aksu River (SW-Turkey). Science of the Total Environment, v.584585, p.131-144, 2017. DOI:

https://doi.org/10.1016/j.scitotenv.2017.01.102

TERÊNCIO, D. P. S.; SANCHES FERNANDES, L. F.; CORTES, R. M. V.; MOURA, J. P.; PACHECO, F. A. L.. Rainwater harvesting in catchments for agro-forestry uses: A study focused on the balance between sustainability values and storage capacity. Science of the Total Environment, v.613-614, p.1079-1092, 2018. DOI: https://doi.org/10.1016/j.scitotenv.2017.09.198

UDHAYAKUMAR, R.; MANIVANNAN, P.; RAGHU, K.; VAIDEKI S.. Assessment of physico-chemical characteristics of water in Tamilnadu. Ecotoxicology and Environmental Safety, v.134, p.474-477, 2016. DOI: https://doi.org/10.1016/i.ecoenv.2016.07.014

ZDEB, M.; AL-KHATIB, I.; GHANNAM, S.; ANAYAH, F.; JODEH S.; HANBALI, G.; KHALAF, B.; VALK, M. V. D.. The quality of rainwater collected from roofs and the possibility of its economic use. Resources, v.9, n.2, 2020. DOI: https://doi.org/10.3390/w11030585

A CBPC - Companhia Brasileira de Produção Científica (CNPJ: 11.221.422/0001-03) detém os direitos materiais desta publicação. Os direitos referem-se à publicação do trabalho em qualquer parte do mundo, incluindo os direitos às renovações, expansões e disseminações da contribuição, bem como outros direitos subsidiários. Todos os trabalhos publicados eletronicamente poderão posteriormente ser publicados em coletâneas impressas sob coordenação da Sustenere Publishing, da Companhia Brasileira de Produção Científica e seus parceiros autorizados. Os (as) autores (as) preservam os direitos autorais, mas não têm permissão para a publicação da contribuição em outro meio, impresso ou digital, em português ou em tradução. 